\title{
PENGENDALIAN KUALITAS OUTSOLE DI LINE PRESS OUTSOLE DEPARTEMENT TECHNICAL PT KMK GLOBAL SPORTS (K2)
}

\author{
ELLYSA KUSUMA LAKSANAWATI'), NANDA PRILLIAN ARIESTA ${ }^{2)}$ \\ Program Studi Tekik Mesin - Fakultas Teknik \\ Universitas Muhammadiyah Tangerang \\ Jl. Perintis Kemerdekaan I/33, Cikokol Kota Tangerang \\ Email: ellysakl@yahoo.com ${ }^{l)}$
}

\begin{abstract}
ABSTRAK
PT. KMK Global Sports 2 merupakan perusahaan yang bergerak dalam bidang manufaktur industri sepatu. Produk yang dihasilkan di PT. KMK Global Sports 2 adalah sepatu dengan merk Converse. Seperti kita ketahui industri sepatu di Indonesia telah mengalami kemajuan yang cukup berarti. Kondisi tersebut diawali dengan produsen sepatu dalam negeri yang umumnya merupakan industri kecil (home industri) dengan kualitas yang masih rendah, kini telah berkembang menjadi produsen sepatu berskala besar yang mampu memproduksi sepatu berstandar internasional oleh karena itu selaku produsen yang memproduksi sepatu PT. KMK Global Sports 2 diharuskan untuk selalu menjaga bahkan meningkatkan kualitas produk. Permasalahan kualitas produk yang ada di Line Hot Press Outsole di Departement Technical, PT KMK Global Sports (K2) yaitu banyaknya defect Outsole yang terjadi pada saat proses produksi. Untuk langkah awal dicari jenis-jenis defect outsole yang ada di PT.KMK Global Sports pada sepatu Converse Japan. Kemudian dicari defect yang paling banyak dengan menggunakan Diagram Pareto. Setelah didapatkan defect yang paling besar kita gunakan diagram Fishbone (Sebab-akibat) untuk menyelesaikan permasalahan yang ada. Dari hasil Diagram Pareto diperoleh defect yang paling besar yaitu defect Kurang Bahan yang kemudian dianalisa permasalahannya menggunakan diagram Fishbone dan diperoleh permasalahan utama dari faktor Manusia, Metode dan Material. Solusi pemecahan masalah yang bisa kita lakukan adalah dengan menggunakan material yang sesuai standar dan harus mengikuti Standard Operasional Prosedure serta dilakukan pengawasan yang ketat sehingga defect tersebut dapat berkurang dan diusahakan tidak terjadi lagi. Hal ini dilakukan untuk meningkatkan kualitas serta meningkatkan kepuasan pelanggan.
\end{abstract}

Kata Kunci: Pengendalian Kualitas, Defect, Pareto, Fishbone, Line Hot Press Outsole, Standart Operational Prosedure.

\section{ABSTRACT}

PT. KMK Global Sports 2 is a company shoe industry manufacturing. Output Products at PT. KMK Global Sports 2 is Converse. As we know, the shoe industry in Indonesia has significant progress. These conditions began with domestic shoe manufacturers, which are generally small industries (home industries) with low quality, now has developed into a large-scale shoe manufacturer that is capable of producing shoes of international standard, therefore as a manufacturer producing shoes PT. KMK Global Sports 2 is required to always maintain and improve product quality. The problem of product quality in the Hot Press Outsole Line at the Technical Department, PT KMK Global Sports (K2) is the number of Outsole defects that occur during the 
production process. For the first step, look for types of defect outsole in PT. KKK Global Sports in Converse Japan shoes. Then look for the big defects using the Pareto Diagram. After we get the biggest defect, we use Fishbone diagram (Cause and effect) to solve the problem. From the results of Pareto Diagram, the biggest defect is defect of Less Material which is analyzed using Fishbone diagram and the main problems founded from the Human, Method and Material factors. The solution to solve the problem is that we can use materials that suitable with standards and must follow the Standard Operating Procedure as well as carry out strict supervision so that defects can be reduced and attempted not to occur again. This is to improve quality and increase customer satisfaction.

Keywords: Quality Control, Defect, Pareto, Fishbone, Hot Press Outsole Line, Standard Operational Procedure.

\section{PENDAHULUAN}

Perkembangan pasar Global menyebabkan persaingan dibidang industri semakin ketat, berbagai perusahaan manufaktur berusaha bersaing untuk menjadi yang lebih unggul dengan cara memberikan pelayanan yang terbaik untuk mencapai kepuasan yang diinginkan para konsumen. Mereka berusaha mengendalikan dan meningkatkan kualitas produksinya sehingga memiliki nilai jual yang tinggi.

Oleh karena itu perbaikan berkelanjutan dilakukan oleh banyak perusahaan agar dapat mendorong peningkatan pasar dan memenangkan persaingan, perusahaan yang tidak megelola perubahan tersebut akan tertinggal.

Untuk menghasilkan produk yang unggul bukan hanya diatasi dengan perbaikan produk yang dihasilkan melainkan terlebih dahulu memperbaiki proses yang dilalui dalam pembuatan produk. Perusahaan juga dituntut untuk menggunakan sistem manajemen yang baik, dalam sistem manajemen ini dapat dijadikan alat untuk meningkatkan kinerja perusahaan melalui kinerja karyawannya. Diharapkan karyawan dapat menjadikan kualitas bagian dari jiwanya sehingga mereka dapat memberikan performance yang terbaik untuk menghasilkan produk yang berkualitas.

Begitu juga halnya yang terjadi diperusahaan PT. KMK Global Sports (K2) sebuah perusahaan yang bergerak dibidang industri sepatu. Untuk menghadapi persaingan global dengan negara lain, perusahaan ini diharuskan melakukan perbaikan yang berkelanjutan mengenai kualitas.

Pengamatan terfokus kepada permasalahan proses produksi yang ada di Line Hot
Press Outsole di Departement Technical, PT KMK Global Sports (K2) yaitu banyaknya defect Outsole yang terjadi pada saat proses produksi.

Penelitian dilakukan dengan menganalisa penyebab dari Permasalahan defect Outsole tersebut karena bila hal tersebut terjadi secara terus-menerus akan mengakibatkan pemborosan serta kerugian yang sangat besar seperti kerugian pembelian bahan baku, kerugian waktu, kerugian pengupahan tenaga kerja, kerugian biaya produksi dan kerugian yang terutama adalah kehilangan kepercayaan konsumen karena kualitas produk yang buruk.

Dari penelitian yang dilakukan, diharapkan dapat memberikan perbaikan-perbaikan berkelanjutan dengan menghasilkan proses yang efektif, biaya yang minimal, produk yang berkualitas, pengiriman yang tepat waktu, dan harga jual yang murah sehingga dapat mencapai tujuan yaitu memberikan kepuasan kepada konsumen dan juga memberikan profit yang besar untuk perusahaan.

\section{KAJIAN PUSTAKA}

\section{a. Pengertian Pengendalian kualitas}

Hari Purnomo (2004:242) menjelaskan "Pengendalian kualitas adalah aktivitas pengendalian proses untuk mengukur ciri-ciri kualitas produk,membandingkannya dengan spesifikasi atau persyaratan,dan mengambil tindakan penyehatan yang sesuai apabila ada perbedaan antara penampilan yang sebenarnya dan yang standar."

Menurut Rosnani Ginting, dalam bukunya berjudul sitem produksi (2007:301), pengendalian kualitas merupakan suatu sis- 
tem verifikasi dan penjagaan/perawatan dari suatu tingkat/derajat kualitas produk atau proses yang dikehendaki dengan perencanaan yang seksama,pemakaian peralatan yang sesuai, inspeksi yang terus menerus serta tindakan korektif bilamana diperlukan. Sedangkan menurut Vincent Gasperz (2005:480), pengendalian adalah:

Control can mean an evaluation to indicate needed corrective responses, the act guilding, or the state of process in which the variability is attribute to a constant system of chance couses. Jadi pengendalian dapat diartikan sebagai kegiatan yang dilakukan untuk memantau aktivitas dan memastikan kinerja sebenarnya yang dilakukan telah sesuai dengan yang direncanakan.

Selanjutnya pengertian pengendalian kualitas dalam arti menyeluruh adalah sebagai berikut: Pengertian pengendalian kualitas menurut Sofjan, 1998:210, adalah: Pengawasan mutu merupakan usaha untuk mempertahankan mutu/ kualitas dari barang yang dihasilkan, agar sesuai dengan spesifikasi produk yang telah ditetapkan berdasarkan kebijaksanaan pimpinan perusahaan.

Berdasarkan pengertian di atas, maka dapat ditarik kesimpulan oleh Penulis bahwa pengendalian kualitas adalah suatu teknik perbaikan dengan cara mengontrol standar mutu produk yang diproduksi,mencari permasalahan yang ada dilapangan, mempertahankan kualitas yang sudah baik, memperbaiki permasalahan kualitas produk secara berkelanjutan sesuai dengan standard yang diberikan perusahaan dan standard kepuasan konsumen.

\section{b. Tujuan Pengendalian Kualitas}

Tujuan dari pengendalian kualitas menurut Sofjan (1998:210) adalah:

1. Agar barang hasil produksi dapat mencapai standar kualitas yang telah Ditetapkan

2. Mengusahakan agar biaya inspeksi dapat menjadi sekecil mungkin.

3. Mengusahakan agar biaya desain dari produk dan proses dengan menggunakan kualitas produksi tertentu dapat menjadi sekecil mungkin.

4. Mengusahakan agar biaya produksi dapat menjadi serendah mungkin.
Jadi Tujuan utama pengendalian kualitas adalah menjamin bahwa barang atau jasa yang dihasilkan sudah sesuai dengan standar kualitas yang telah ditetapkan sehingga mengurangi biaya produksi seminimal mungkin dan meningkatkan kualitas pada proses manufacturing.

\section{c. Defect Produk}

Merupakan kejadian dimana produk gagal atau tidak sesuai dengan spesifikasi yang diinginkan oleh perusahaan dan gagal memenuhi persyaratan yang diinginkan pelanggan. Merupakan produk yang tidak diharapkan oleh perusahaan karena akan menimbulkan pemborosan.

\section{d. Pengendalian Kualitas dengan Seven Tool}

Seven tool adalah 7 (tujuh) alat statistik utama yang dapat digunakan sebagai alat bantu untuk mengendalikan kualitas. Menurut Rosnani Ginting (2007:304) Fungsi Tujuh alat pengendalian kualitas adalah meningkatkan kemampuan perbaikan proses, sehingga akan diperoleh:

a. Peningkatan kemampuan berkompetensi

b. Penurunan cost of quality dan peningkatan fleksibilitas harga.

c. Meningkatkan produktivitas sumber daya.

Adapun ketujuh alat pengendalian kualitas yang salah satunya dapat kita gunakan seperti:

1) Lembar Pemeriksaan (Check Sheet)

Check sheet merupakan alat praktis yang digunakan untuk mengumpulkan, mengelompokan, dan menganalisa data secara mudah Tujuan pembuatan lembar pemeriksaan adalah memastikan bahwa data dikumpulkan secara teliti dan akurat oleh karyawan operasional untuk di adakan pengendalian proses dan penyelesaian masalah. Pemeriksaan dibuat berdasarkan harian dan mingguan.

\section{2) Histogram (Diagram Batang)}

Histogram adalah salah satu metode statistik untuk mengatur data sehingga dapat dianalisa dan diketahui distribusinya. Histogram memiliki Kegunaannya untuk mengetahui distribusi/penyebaran data yang ada. Histogram merupakan tipe grafik batang dimana sejumlah data dikelompokkan kedalam beberapa kelas dengan interval tertentu, 
histogram langkah penyusunan histogram adalah:

1. Menentukan batas-batas observasi, misalnya perbedaan antara nilai terbesar dan terkecil

2. Memilih kelas-kelas atau sel-sel, biasanya,dalam menentukan banyaknya kelas, apabila $\mathrm{n}$ menunjukan banyaknya data, maka banyaknya kelas ditunjukan dengan $\sqrt{n}$

3. Menetukan lebar kelas-kelas tersebut. Biasanya, semua kelas mempunyai lebar yang sama. Lebar kelas ditentukan dengan membagi range dengan banyaknya kelas.

4. Menentukan batas-batas kelas. Tentukan banyaknya observasi pada masing-masing kelas dan yakinkan bahwa kelaskelas tersebut tidak saling tumpang tinduh.

5. Menggambar frekuensi histogram dan menyusun diagram batangnya.

\section{3) Control Chart}

Peta pengendali menggambarkan perbaikan kualitas. Perbaikan kualialitas terjadi pada dua situasi.situasi pertama adalah ketika peta kendali dibuat, proses dalam kondisi tidak stabil.kondisi yang diluar batas kendali terjadi karena sebab khusus (assignable cause), kemudian dicari tindakan perbaikan sehingga proses menjadi stabil. Hasilnya adalah adanya perbaikan proses. Kondisi kedua berkaitan dengan pengujian. Peta pengendali tepat bagi pengambil keputusan karena model akan melihat yang baik dan yang buruk. Peta kendali memang tepat dalam penyelesaian masalah melalui perbaikan kualitas,walaupun ada kelemahan apabila digunakan untuk memonitor atau mempertahankan proses. Peta control memiliki kegunaan yaitu:

1. Mengetahui apakah ada tidaknya perubahan proses produksi

2. Menentukan spesifikasi.

3. Mengontrol proses produksi

Berdasarkan data yang digunakan, peta control terdiri dari:

a. Peta control variable (kuantitatif), misalnya:

1. Peta $\overline{\mathrm{X}}$ dan $\mathrm{R}$

2. Peta $\bar{X}$ dan MR

\section{Peta $\bar{X}$ dan $S$}

b. Peta control atribut (tidak kuantitatif), misalnya:

1. Peta $\mathrm{p}$

2. Peta np

3. Peta $\mathrm{c}$

4. Peta u

\section{4) Diagram Pareto}

Merupakan metode untuk menentukan masalah mana yang harus dikerjakan terlebih dahulu. Pareto Chart, mendasarkan keputusannya pada data kuantitatif. Diagram Pareto dibuat untuk menemukan atau mengetahui masalah atau penyebab yang merupakan kunci dalam penyelesaian masalah dan perbandingan terhadap keseluruhan. Dengan mengetahui penyebab-penyebab yang dominan maka kita akan bisa menetapkan prioritas perbaikan. Selain itu, diagram pareto juga dapat digunakan untuk membandingkan kondisi proses, misalnya ketidaksesuaian proses sebelum dan setelah diambil tindakan perbaikan terhadap proses. Penyusunan diagram pareto sangat sederhana, proses penyusunan diagram pareto meliputi enam langkah yaitu:

1. Kumpulkan data dan susun data berdasarkan jumlah yang paling besar ke yang paling kecil/tentukan jumlah kumulatifnya.

2. Gambar Grafik dengan sumbu Y sebagai jumlah data dan sumbu $X$ sebagai katagori data dan digambar dengan skala tepat.

3. Gambarkan diagram batang pada sumbu $\mathrm{X}$ sesuai katagori data dan jumlahkan mulai dari jumlah data terbesar sampai terkecil.

4. Dengan menggunakan tabel kumulatif gambar grafik kumulatifnya.

Setelah didapat diagram pareto maka dapat kita simpulkan katagori yang paling dominan dari tiap kategori.

Kegunaan Diagram Pareto yaitu:

1. Menunjukkan persoalan utama.

2. Menyatakan perbandingan masing-masing persoalan terhadap keseluruhan.

3. Menunjukkan tingkat perbaikan setelah adanya tindakan perbaikan.

4. Menunjukkan perbandingan masing-masing persoalan sebelum dan sesudah perbaikan. 
5) Diagram Sebab akibat (fishbone Chart)

Diagram ini dikenal Diagram sebabakibat menggambadengan istilah diagram tulang ikan (fishbone chart) yang diperkenalkan pertama kalinya oleh Prof. Kaoru Ishikawa (Tokyo University) pada tahun 1943. (Rosnani,2007:307). Diagram tersebut memang digunakan untuk mengetahui sebabakibat dari suatu masalah untuk selanjutnya diambil tindakan perbaikan. Fungsi dasarnya adalah untuk mengindentifikasi dan mengorganisasi penyebab-penyebab yang mungkin timbul,diagram tulang ikan (fishbone chart) dan berguna untuk memperlihatkan faktor-faktor utama yang berpengaruh pada kualitas dan mempunyai akibat pada masalah yang kita pelajari. Selain itu kita juga dapat melihat faktor-faktor yang lebih terperinci yang berpengaruh dan mempunyai akibat pada faktor utama tersebut yang dapat kita lihat dari panah-panah yang berbentuk tulang ikan pada diagram fishbone tersebut. Untuk mencari faktor-faktor penyebab terjadinya penyimpangan kualitas hasil kerja,maka orang akan selalu mendapatkan bahwa ada 5 faktor penyebab utama yang signifikan yang perlu diperhatikan,yaitu:

1. Manusia (Man)

2. Metode kerja (Work method)

3. Mesin atau peralatan kerja lainnya (Machine/Equipment)

4. Bahan-bahan baku (Raw Material)

5. Lingkungan kerja (Work Environment)

Adapun kegunaan dari diagram sebab akibat adalah:

1. Membantu mengidentifikasi akar penyebab masalah.

2. Menganalisa kondisi yang sebenarnya yang bertujuan untuk memperbaiki peningkatan kualitas.

3. Membantu membangkitkan ide-ide untuk solusi suatu masalah.

4. Membantu dalam pencarian fakta lebih lanjut.

5. Mengurangi kondisi-kondisi yang menyebabkan ketidaksesuaian produk dengan keluhan konsumen.

6. Menentukan standarisasi dari operasi yang sedang berjalan atau yang akan dilaksanakan.

7. Sarana pengambilan keputusan dalam menentukan pelatihan tenaga kerja.

8. Merencanakan tindakan perbaikan.
Langkah-langkah dalam membuat diagram sebab akibat adalah sebagai berikut:

1. Mengidentifikasi masalah utama.

2. Menempatkan masalah utama tersebut disebelah kanan diagram.

3. Mengidentifikasi penyebab minor dan meletakannya pada diagram utama.

4. Mengidentifikasi penyebab minor dan meletakannya pada penyebab mayor.

5. Diagram telah selesai, kemudian dilakukan evaluasi untuk menentukan penyebab sesungguhnya.

\section{6) Diagram Scatter}

Diagram Pencar merupakan diagram yang menggambarkan korelasi (hubungan) antara 2 faktor atau data yang ada. Dengan memakai diagram ini kita dapat melihat apakah 2 faktor yang kita uji tersebut saling berpengaruh mempunyai korelasi atau tidak.

7) Stratification (Stratifikasi/Pengelompokan Data)

Stratification merupakan usaha pengelompokan data ke dalam kelompok-kelompok yang mempunyai karakteristik yang sama,

Kegunaan dari stratification adalah:

a. Mencari faktor-faktor penyebab utama kualitas secara mudah.

b. Membantu pembuatan Scater Diagram

c. Mempelajari secara menyeluruh masalah yang dihadapi

Memperbaiki kerusakan adalah pekerjaan yang sulit jika tidak ada stratification data. Kriteria Stratification yang efektif adalah:
a. Jenis kerusakan
b. Sebab kerusakan
c. Lokasi kerusakan
d. Material
e. Produk
f. Tanggal membuatnya
g. Kelompok kerja
h. Operator perorangan
i. Supplier bahan
j. $\quad$ Supplier suku cadang

Adapun langkah-langkah stratifikasi adalah sebagai berikut:

a. Menentukan tujuan dari pelaksanaan stratifikasi, seberapa detilkah stratifikasi yang perlu dilakukan

b. Menentukan seluruh faktor dan kriteria yang akan digunakan dalam stratifikasi. 
c. Membuat kelompok-kelompok an sub kelompok berdasarkan ketidaksamaan yang paling penting diantara faktor misalnya mula-mula dibagi berdasarkan penyebab kerusakan (kerusakan oleh operator atau oleh mesin).

d. Memasukan tiap faktor kedalam kelompok dan sub kelompok yang sesuai.

\section{HASIL DAN PEMBAHASAN}

\section{a. Pengumpulan Data}

Berikut adalah flow proses yang terjadi pada line hot press outsole:

\section{Weighing Chemical Dan Polymer}

Pertama adalah bahan rubber dan chemical di timbang di weighing area, di area ini bahan dasar sudah dibuat sesuai komposisi dan takaran yang sudah ditentukan formulasinya oleh departemen technical.

\section{Banbury Mixing Component}

Setelah bahan selesai di timbang, maka bahan dibawa naik ke lantai 2 menggunakan lift untuk diproses oleh mesin banbury. Proses ini adalah proses penggilingan yang berfungsi untuk mengolah rubber dan chemical supaya menyatu menjadi bahan karet.

\section{Open Roll 22" Mixing Component}

Tepat dibawah mesin banbury terdapat mesin open roll 22", dimana mesin open roll 22" akan membentuk bahan menjadi gulungan (roll). Selanjutnya bahan yang membentuk gulungan (roll) diproses ke mesin bacth off.

\section{Batch Off Process}

Batch off process adalah proses yang berfungsi untuk mendinginkan dan membentuk bahan menjadi lembaran atau sheet .Lalu bahan yang telah selesai dalam proses mesin bacth off masuk ke dalam rak fifoagar bahan yang pertama dibuat dapat terlebih dahulu diproses sesuai dengan standart.

\section{Roll 18" Shulpuring}

Proses ini sama dengan proses roll 22" hanya saja ada perbedaan pada mesin yang digunakan, pada proses ini menggunakan mesin yang ukurannya lebih kecil yaitu mesin roll 18". Pada proses ini juga terjadi penambahan sulphur, agar bahan yang akan diproses menjadi lunak dan mudah dibentuk. Setelah proses shulpuring, bahan didiamkan sampai dingin sebelum dilakukan proses ini lagi. Biasanya bahan dingin setelah selesai rheometer dan press test.

\section{Rheometer Dan Press Test}

Rheometer test dilakukan agar dapat mengetahui kematangan bahan dan test press untuk mengetahui warna bahan setelah proses press apakah sesuai dengan standar spesifikasi yang telah ditentukan. Bila bahan lolos test, lalu bahan diproses ulang di mesin roll 18" untuk membetuk gulungan (roll) kecil agar dapat dimasukan kedalam callender 6 yang berfungsi untuk menentukan thickness sesuai dengan standart prefoam.

\section{Callender 6"}

Cara kerja proses mesin ini sama dengan cara kerja pada proses mesin batch off, hanya saja pada mesin ini thickness bahan bisa diatur sesuai standar yang telah ditentukan.

\section{Cutting Prefoam}

Cutting prefoam dilakukan menggunakan mesin cutting untuk memotong bahan sesuai dengan ukuran atau size yang telah ditentukan.

\section{Hot Press Outsole}

Hot press outsole berfungsi untuk mencetak prefoam rubber yang masih lunak dan mentah menjadi outsole yang keras dan matang sesuai spesifikasi yang ditentukan.

\section{Triming Outsole}

Trimming outsole dilakukan untuk merapihkan bentuk dari rubber outsole, membersihkan sekeliling area outsole yang berlebihan.

\section{Buffing Outsole}

Proses buffing outsole adalah untuk mengasarkan permukaan material outsole (rubber) menggunakan mesin gerinda agar mudah diresap lem pada saat di proses di departemen assembling. Selanjutnya outsole dilakukan proses pemeriksaan kualitas melalui mesin detector berfungsi untuk mendeteksi logam dan besi dalam outsole, dan terakhir di paking di kirim gudang outsole.

\section{b. Gambar Defect Outsole}

Dari penelitian ditemukan beberapa macam masalah defect outsole yang sering terjadi, yaitu: 
1. Kurang Bahan, yang sering terjadi bagian samping kanan ataupun samping kiri tidak sesuai mold atau cetakan, terlihat seperti setengah.

2. Kurang Angin, pada bagian outsole ada yang bergelembung

3. Logo berbayang, Logo yang bertulisan Converse dilihat tidak terlalu nyata seperti berbayang.

4. Pecah, permukaan outsole tidak halus karena sebagian outsole ada yang menempel di mold

5. Bahan Kotor, outsole tidak bersih ada noda

Gambar cacat:

1)Kurang Bahan

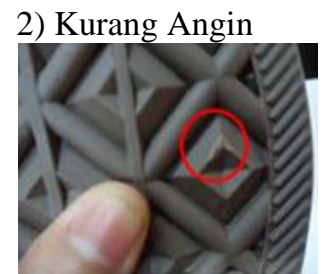

Gambar1.KurangBahan Gambar2. Kurang Angin

3)Logo berbayang

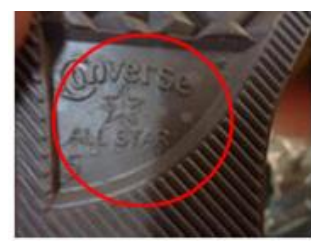

4) Pecah

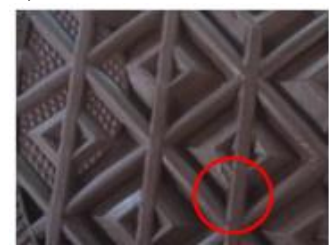

Gambar 3 Logoberbayang Gambar4. Pecah

\section{5)Bahan Kotor}

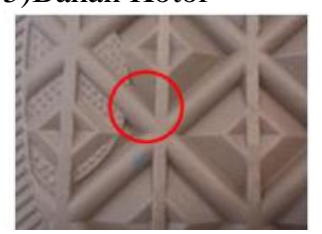

Gambar 5 Bahan Kotor

\section{c. Pengolahan Data}

Tabel 1 Jenis-jenis Defect Bulan Januari 2014

\begin{tabular}{|c|c|c|c|c|}
\hline No & Janis Defect & Jumlah & \% Defect & \% Kumulatif \\
\hline 1 & Kurang Bahan & 302 & $21.07 \%$ & $21.07 \%$ \\
\hline 2 & Bahan Kotor & 236 & $16.47 \%$ & $37.54 \%$ \\
\hline 3 & Kurang Angin & 297 & $20.73 \%$ & $58.27 \%$ \\
\hline 4 & Logo Berbayang & 279 & $19.47 \%$ & $77.74 \%$ \\
\hline 5 & Pecah & 319 & $22.26 \%$ & $100.00 \%$ \\
\hline
\end{tabular}

Tabel 2 Input, Defect dan \% Defect Outsole untuk Bulan Januari s/d Desember 2014
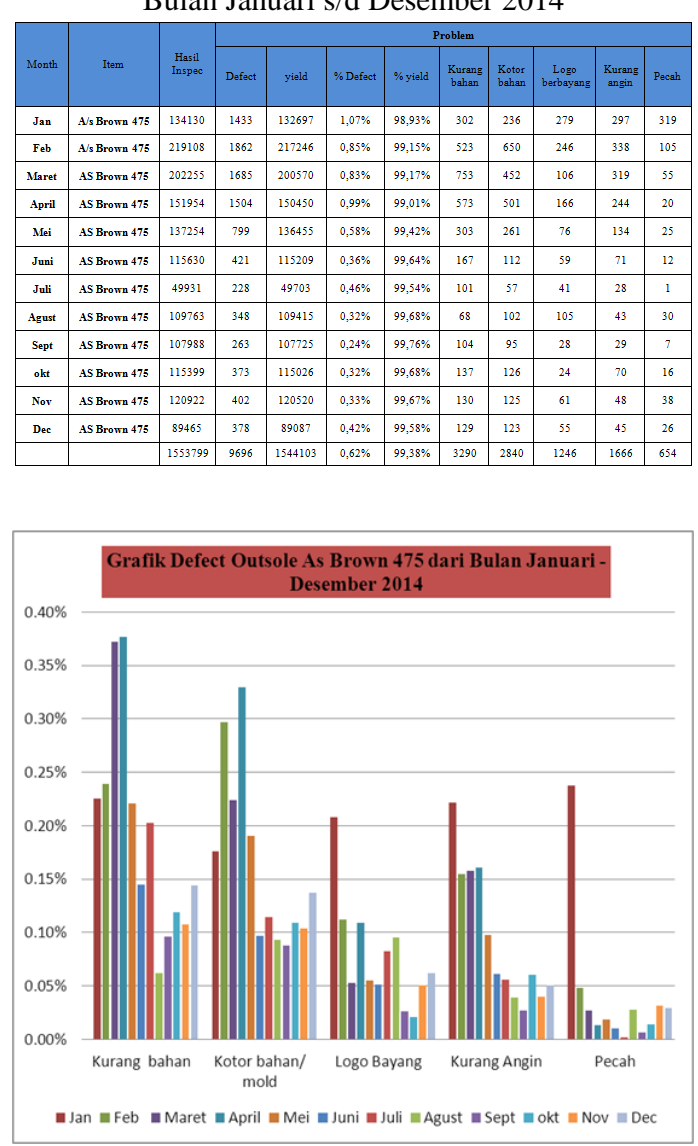

Gambar 6 Data Defect Outsole dari Bulan Januari s/d Desember 2014

Dari grafik diatas dapat disimpulkan bahwa dari bulan Januari s/d Desember 2014 Defect yang paling banyak terjadi dan tertinggi adalah Kurang Bahan. Untuk mengetahui penyebab terjadinya kurang bahan, dibuatlah diagram fishbone. Data diambil dari utilisasi waktu dan survey lapangan.

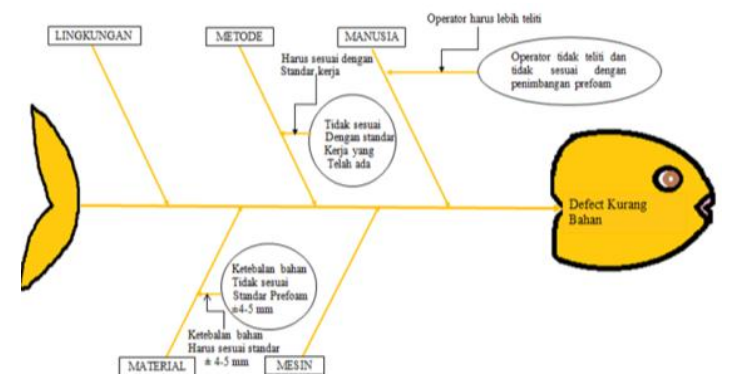

Gambar 7 Diagram Fishbone

Dari diagram fishbone diketahui bahwa defect outsole disebabkan oleh:

1. Faktor Manusia:

a. Operator tidak teliti pada saat memasukan prefoam ke dalam mold, 
seharusnya operator menimbang terlebih dahulu.

b. Operator kurang mendapat training dari perusahaan terutama dari departmen technical yang terkait tentang training proses pembuatan outsole.

\section{Faktor Metode}

Tata cara penempatan bahan tidak sesuai standar, penempatan bahan tidak menutupi seluruh bagian lubang mold atau cetakan outsole yang mengakibatkan hasil press Outsole menjadi defect kurang bahan.

3. Faktor Lingkungan

Faktor Lingkungan, tidak menyebabkan defect kurang bahan

4. Faktor Mesin

Faktor Mesin,tidak menyebabkan defect kurang bahan.

5. Faktor Material

Kertebalan bahan outsole lebih tipis dibawah standar, standar yang sudah di tentukan oleh departemen IE dan Technical yaitu $\pm 4-5 \mathrm{~mm}$.

\section{KESIMPULAN DAN SARAN}

Dari hasil analisis yang dilakukan pada bab-bab sebelumnya, dapat diambil beberapa kesimpulan sebagai berikut:

1. Berbagai jenis cacat yang mungkin terjadi pada saat produksi antara lain:

1) Kurang Bahan

2) Bahan Kotor

3) Logo Berbayang

4) Kurang Angin

5) Pecah

2. Dilihat dari data defect bulan Januari s/d Desember 2014 permasalahan kualitas pada Line Hot Press Outsole yang dominan, adalah defect kurang bahan (dari diagram fishbone) yang disebabkan oleh tiga faktor yaitu:

1) Faktor manusia, operator tidak teliti pada saat sebelum memasukan prefoam ke dalam mold, seharusnya operator menimbang terlebih dahulu.

2) Faktor metode, tata cara penempatan bahan tidak sesuai standar, penempatan bahan tidak menutupi seluruh bagian lubang mold atau cetakan outsole yang mengakibatkan hasil press outsole menjadi defect kurang bahan.
3) Faktor material,

Kertebalan bahan outsole lebih tipis dibawah standar, standar yang sudah di tentukan oleh departemen IE dan Technical yaitu $\pm 4-5 \mathrm{~mm}$.

Saran

Saran yang dapat penulis sampaikan setelah melakukan analisa dan pengamatan di PT. KMK Global Sports 2 yang mungkin dapat bermanfaat bagi institusi maupun bagi pembaca, yaitu:

1. Elemen Manusia pada diagram fishbone.

Perlu dilakukan training atau pelatihan terhadap operator mengenai penggunaan standar sebagai dasar dalam melakukan penimbangan prefoam saat memasukan prefoam ke dalam mold, dikarenakan masih tidak konsisten dalam melakukan penimbangan prefoam.

2. Elemen Material pada diagram fishbone Perlu adanya control dalam pengukuran ketebalan bahan agar bahan dapat berstandart sesuai dengan spesifikasi ketebalan prefoam outsole yang sudah di tentukan Departemen IE dan Technical.

3. Elemen Metode pada diagram fishbone

4. Operator harus mengikuti standart operasional prosedur pada proses press outsole serta mengikuti penimbangan sesuai dengan standart per size.

5. Dilakukan pengawasan yang ketat terhadap proses produksi.

\section{DAFTAR PUSTAKA}

Assauri, Sofjan. 1998. Manajemen Operasi dan Produksi. Jakarta: LP FE UI

Gasperz, Vincent. 2005. Total Quality Management. Jakarta: PT. Gramedia Pustaka Utama

Purnomo, Hari.2004. Pengantar Teknik Industri.Yogyakarta: Graha ilmu

Sadikin, Fransiscus xaverius.2005.Tip dan Trik Meningkatkan Efisiensi, Produktivitas, dan Profitabilitas. Yogyakarta: Andi

Ginting, Rosnani. 2007. Sistem Produksi.Yogyakarta: Graha ilmu

J.M Juran. 1988. Juran's Quality Control Handbook $1 \& 2$, 4th edition, McGraw Hill, Inc. 